\title{
Approach to the aphthous lesions of the oral mucosa
}

\author{
Oral mukozanın aftöz lezyonlarına yaklaşım
}

\author{
Deniz Aksu Arica' ${ }^{10}$, Arzu Ferhatosmanoglu' 1 \\ ${ }^{1}$ Dept. of Dermatology, Karadeniz Technical University Faculty of Medicine, Trabzon, Turkey
}

\begin{abstract}
Aphthous oral cavity lesions are common in clinical practice that negatively affect the quality of life. It is possible to reveal the etiological cause in aphthous lesions, with detailed history, physical examination findings, and appropriate laboratory evaluation. In this article, we aimed to review the differential diagnosis by examining the conditions that need to be questioned with clinical clues to reveal the correct etiological cause in a patient presenting with the complaint of oral aphthae.
\end{abstract}

Key words: oral ulcer, stomatitis, diagnosis

\section{O̊zet}

Oral kavitenin aftöz lezyonları klinik pratikte sıklıkla karşılaşılan hayat kalitesini olumsuz yönde etkileyen bir durumdur. Aftöz lezyonlarda etiyolojik nedenin ortaya konulabilmesi ayrıntılı anamnez, fizik muayene bulguları ve uygun laboratuvar değerlendirme ile mümkündür. Bu derlemede oral aft şikayetiyle başvuran bir hastada doğru etyolojik nedenin ortaya konulabilmesi için sorgulanması gereken durumlar, klinik ipuçlarıyla irdelenerek ayırıcı tanının gözden geçirilmesi amaçlanmıştır.

Key words: oral ülser, stomatit, tanı

\section{Introduction}

Painful oral aphthous ulcers are commonly referred to as aphthae or canker sores. ${ }^{1}$ They are characterized by an erythematous halo surrounding the ulcer and a fragile, yellowish-white fibrinous exudate covering the necrotic base..$^{2,3}$ Ulceration of the oral cavity may be a presenting sign of a broad spectrum of diseases such as inflammatory bowel disease, Behçet's disease, Human Immunodeficiency Virus (HIV) infection, systemic lupus erythematosus (SLE), and neutropenia, etc. ${ }^{4}$ Ulcers lasting less than four weeks, which may progress as a single attack or recurrent attacks, are defined as acute oral ulcers. ${ }^{5}$ Infective causes and recurrent aphthous stomatitis are among the most common causes of acute oral ulcers. Ulcers that persist for more than four weeks are considered as chronic oral ulcers. Chronic inflammatory diseases, autoimmune bullous dermatoses, and malignancies can cause this condition. ${ }^{5}$

Corresponding author: Deniz Aksu Arica, Dept. of Dermatology, Karadeniz Technical University Faculty of Medicine, Trabzon, Turkey Phone: +90 46237751 27, E-mail:drdenizaksu@gmail.com

Received: 2 March 2021 Accepted: 23 March 2021

Conflicts of Interest: None

Funding: None

How to cite this article: Aksu Arica D, Ferhatosmanoglu A. Approach to the aphthous lesions of the oral mucosa. Mucosa 2021;4:1-9

(c) (i) (8) This work is licensed under a Creative Commons Attribution-NonCommercial 4.0 International License. 
When dealing with aphthous ulcerations, the length of time of the lesions, frequency of episodes, inciting or triggering conditions, medications, accompanying systemic symptoms such as fever and arthritis should be questioned. ${ }^{4}$ Table 1 summarizes the conditions that should be questioned in a patient presenting with oral aphthae. In physical examination, the number, type, location, size of the lesions, the base's consistency (soft or hard), and fixation to the underlying structures should be evaluated. ${ }^{3}$ The initial laboratory tests should

Table 1. Initial questioning in a patient with an oral ulcer may include the following items

\section{Initial questioning items}

Accompanying subjective symptoms, like pain

Ulceration site in the oral mucosa

Ulcer size, number, and type

Healing time for past ulcers

Medicines

Predisposing factors

The presence of any of these

Ocular, musculoskeletal, gastrointestinal, neurologic or skin findings

Family history for Behçet's disease, inflammatory bowel disease or Celiac disease

Immunocompromised condition, $\mathrm{HCV}$ or HIV seropositivity, weight loss

include a complete blood count and ferritin levels. Laboratory assessment can be extended according to the patient's anamnesis. Histopathological and immunofluorescence evaluation should be planned for lesions that do not regress within a month. Table 2 summarizes the etiological factors that should be evaluated in a patient presenting with oral ulcers.

\section{Recurrent aphthous stomatitis and asso- ciated conditions}

Recurrent aphthous stomatitis (RAS) is the most common cause of mouth ulcers. ${ }^{6}$ The prevalence range is between $5-66 \%{ }^{7}$ It occurs more frequently in women. ${ }^{8}$ RAS accounts for $25 \%$ of recurrent ulcers in adults and $40 \%$ in children. ${ }^{9}$

It is characterized by the recurrent development of discrete, painful ulcers predominantly located on the

Table 2. The etiological factors that should be evaluated in a patient presenting with oral ulcers

Etiological factors

Recurrent aphthous stomatitis and associated conditions

Ulcerations of infective etiology: bacterial, viral and fungal causes

Erythema multiforme and medication-related ulcerations

Vesiculobullous disorders

Trauma

Neoplasia

Behçet's disease

Lichen planus

buccal mucosa, mouth floor, and ventral surface of the tongue. ${ }^{10}$ Minor, major, and herpetiform types of lesions were described in the literature. , $^{3,11,12}$

Minor RAS lesions are 1 to $10 \mathrm{~mm}$ in diameter, usually confined to the lips, tongue, and buccal mucosa, and spontaneously heal within 10 to 14 days without scarring. ${ }^{9}, 13$ Aphthae that are larger than $10 \mathrm{~mm}$ in diameter are called major aphthae. Major aphthae can last up to 6 weeks to heal and tend to leave a 
scar. ${ }^{13}$ Major aphthous ulcers commonly extend to the gingiva and pharyngeal mucosa. ${ }^{1}$ Aphthae that are less common, less than $2 \mathrm{~mm}$ in diameter, but usually coalesce to form large ulcers with irregular borders and heal without scarring are called herpetiform aphthae. ${ }^{1,5}$ Herpetiform aphthae typically resolve within one month. ${ }^{1}$

Severe RAS lesions can cause chronic pain, malnutrition, and weight loss. ${ }^{14}$ It can also impair speech and swallowing. ${ }^{13}$ The etiology is unclear, but possible contributing factors are local and systemic conditions, genetic, immunological causes, foods, drugs, hormones, stress, nutritional deficiencies, and microbial factors. ${ }^{15,16}$ In epidemiological studies, family history has been reported in $24 \%$ to $46 \%$ of patients. ${ }^{17}$ People with a positive family history of RAS are prone to develop a more severe disease type with more frequent recurrences than the subjects with no family history. ${ }^{17}$ Nutritional deficiencies, especially in iron, group B vitamins, vitamin $C$, folate, or zinc may contribute to RAS. ${ }^{18}$ If necessary, replacement therapies should be done. In a study involving 40 patients with RAS, serum zinc levels were low in $42.5 \%$ of the patients. It was shown in this study that after one month of zinc treatment (220 mg of zinc sulfate once a day), aphthae were reduced and did not reappear for three months. ${ }^{19}$ In another study, vitamin B1, B2, and B6 levels were examined. Vitamin B deficiency was found in $28.2 \%$ of patients with RAS, and significant improvement was observed in patients receiving replacement therapy. ${ }^{20}$

If there are foods that are thought to trigger RAS or delayed recovery, avoiding these foods should be recommended (acidic, salty, spicy foods, peanuts, chocolate, tomatoes, or alcoholic beverages). A food diary should be kept in order to detect the agent. Methods such as specific IgE tests, skin prick tests, skin patch tests can be used to detect food allergies associated with RAS. Hard foods that may cause trauma, biting lips or cheeks, brushing teeth with stiff brushes, and toothpaste containing sodium lauryl sulfate are among the local triggering factors. Non-steroidal anti-inflammatory drugs, antibiotics, beta-blockers, and angiotensin-converting enzyme inhibitors may also cause RAS. ${ }^{15,21}$ Emotional stress and menstrual cycle can trigger RAS attacks. ${ }^{21}$ In the study of Tüzün et al., a negative epidemiological relationship was found between RAS and smoking. ${ }^{22}$ According to the literature, the protective effect of smoking on RAS was only noticed in heavy smokers or persons who smoked for more extended periods. ${ }^{23}$

Celiac disease, Crohn's disease, and ulcerative colitis may have an association with RAS, and these should be considered in patients with gastrointestinal complaints. ${ }^{21}$ Systemic immunosuppressing conditions such as HIV may cause RAS-type ulcers. ${ }^{24}$ Conditions such as Behçet's disease, mouth and genital ulcers with inflamed cartilage (MAGIC), and Reiter's syndromes should be included in the differential diagnosis in patients with a history of other mucocutaneous and systemic complaints such as genital ulcerative lesions, papulopustular eruptions, erythema nodosum, uveitis and arthritis. ${ }^{21}$ Autoinflammatory syndromes such as periodic fever, aphthous stomatitis, pharyngitis, and adenopathy (PFAPA) syndrome; cyclic neutropenia; and hyperimmunoglobulin D (hyper IgD) syndrome should be kept in mind in the presence of fever, malaise or other systemic symptoms. ${ }^{4}$

\section{Ulcerations of infective etiology: bacterial, viral and fungal causes}

\section{Bacterial infections}

Syphilis is a sexually transmitted disease caused by Treponema pallidum. The lesion of primary syphilis may begin as a papule after an incubation period, which can vary between 10-90 days, that may progress to a hard, painless, non-purulent, clean-based ulcer. Although the genital areas are the most common ulceration site, primary syphilis may also cause ulceration in the oral mucosa, depending on the contact area. Oral chancres of syphilis most often involve the lips and typically involute in 3-8 weeks. ${ }^{25,26}$ Oral ulcers may also be observed in the secondary and tertiary stages of the disease. Oral ulcers are painless and heal spontaneously in 2 to 10 weeks in secondary syphilis. ${ }^{27}$ 
In tertiary syphilis, gumma may present as ulcerations, especially on the hard palate and tongue. Gummatous syphilis can destruct bone, perforate palate and leave scars. ${ }^{25}$ When deemed necessary, suspicious sexual contact history should be questioned, and appropriate laboratory tests should be requested.

Tuberculosis (TB) is caused by Mycobacterium tuberculosis. Oral lesions are most commonly seen as ulcers. Oral TB may be either primary or secondary. Primary TB, which is most common in children, appears as a painless ulcer, while secondary $\mathrm{TB}$ is most commonly seen in adults with pulmonary or gastrointestinal TB and presents with painful ulcers. ${ }^{28}$ Tubercular ulcers are long-lasting, slowly increasing in size, and do not tend to heal. ${ }^{28}$

\section{Viral infections}

Herpes simplex virus (HSV) type 1 and HSV type 2 both induce ulceration, but HSV type 1-related ulcerations occur in the oral mucosa more frequently. ${ }^{29}$ Primary herpetic gingivostomatitis is an acute onset of the primary form of HSV that occurs mainly between the ages of six months and five years. ${ }^{30}$ Mild fever, malaise, local lymphadenopathy may be seen in some patients. Lips, gingivae, palate, or tongue may be affected. ${ }^{29}$

Secondary herpetic stomatitis, usually seen in adolescents and adults, may be precipitated by sunlight, trauma (including dental treatments), menstruation, and emotional stress. ${ }^{5}$ Unlike a primary infection, symptoms such as fever, malaise, and lymphadenopathy are not accompanied. ${ }^{5}$ Herpetic lesions are characterized by grouped vesiculations that may rupture and ulcerate with jagged edges in a localized area. The condition is generally self-limited and resolves within 7-10 days without scarring.

Coxsackievirus A is a causative agent of hand, foot, and mouth disease, which generally affects children and adults, and is characterized by herpetiform ulcers, especially in the soft palate and uvula, unlike HSV. ${ }^{5}$ It regresses spontaneously within 7-10 days.

Varicella is a primary infection of varicella-zoster virus (VZV) that classically affects the skin. The lips, buccal mucosa, and palate are the most common sites if oral ulcerations occur in severe disease. ${ }^{31}$ Zoster occurs in older or immunosuppressed patients as a recurrent infection of varicella. Oral mucosal findings are characterized by crusting of erythematous macules and vesicles unilaterally distributed.

Oral ulcerations with Cytomegalovirus (CMV) not common; however, it may present with non-specific widespread ulcerated lesions in the oral mucosa. These non-specific ulcerations mainly occur in immunosuppressed patients and most commonly affect the hard palate, soft palate, tongue, and mouth floor. ${ }^{32}$

Recurrent aphthous ulcers are seen with a frequency of $0.6-13.6 \%$ in HIV-infected patients. Most of these had a CD4 cell count of fewer than 100 cells per mm. ${ }^{33}$ Oral ulcers usually heal with antiretroviral therapy, and the incidence of oral ulcers was significantly reduced with antiretroviral treatments. ${ }^{34,35}$

Epstein-Barr virus (EBV)-positive mucocutaneous ulcers are self-limiting, silent ulcers associated with immunosuppression, generally responding well to conservative treatment. ${ }^{36}$ It is essential to distinguish it from HIV-associated oral ulcers. ${ }^{37}$

\section{Fungal infections}

Various fungal infections can cause oral ulcerations, especially in immunocompromised patients. Blastomycosis infection in oral mucosa may show erythematous, irregular, rolled borders and mimics squamous cell carcinoma. ${ }^{4}$ Histoplasmosis often starts as erythematous macules located on the gingiva, palate, and tongue and forms painful ulcerative lesions. ${ }^{38}$ In immunosuppressed patients, aspergillus most often involves the palate and tongue. Painful ulcerative lesions with the yellow-black necrotic area are characteristic. ${ }^{4}$ Cryptococcal oral mucosal lesions are extremely rare and have been reported mainly in Acquired Immunodeficiency Syndrome (AIDS) patients. It can be seen as a tongue-palate ulcer, an ulcer that does not heal after tooth extraction, or hyperplastic tissue-mimicking benign or malignant tumor on the oral mucosa. ${ }^{39}$ 


\section{Erythema multiforme and medication-related ulcerations}

Erythema multiforme (EM) is an immune-mediated abnormal T-cell response characterized by cutaneous targetoid lesions and mucosal erosive or ulcerative lesions. ${ }^{40}$ Oral lesions occur more than $70 \%$ of patients. ${ }^{41}$ EM is most commonly associated with infective agents such as HSV, Mycoplasma pneumoniae, and EBV., ${ }^{4,40}$ Medications like non-steroidal antiinflammatory drugs (NSAIDs), antibiotics, antifungals and antivirals, malignancies, radiation exposures, immunizations, foods, and hormones are the other possible etiologic factors. ${ }^{40}$

Stevens-Johnson syndrome / toxic epidermal necrolysis (SJS/TEN) is a severe mucocutaneous reaction mostly caused by drugs. Other potential etiologies include infections (Mycoplasma pneumoniae, HSV, HIV, influenza virus, hepatitis viruses, group A beta-hemolytic streptococci, etc.), malignancies, and vaccinations. ${ }^{42}$ Mucosal involvement can occur before or after skin rash in more than $90 \%$ of patients. Following one to three weeks after taking the responsible drug (antibiotics, NSAIDs, and anticonvulsants), cutaneous lesions appear as tender, erythematous, dusky macules with a positive nikolsky sign. ${ }^{1}$ Diffuse oral, ocular and genital mucosal involvement may be present. Labial mucosa, buccal mucosa, tongue, mouth floor, and the soft palate are the most common involvement sites. Burning sensation, erythema of the lips and buccal mucosa, and the hemorrhagic crusting of the vermillion zone of the lips are some of the accompanying complaints and signs.

Fixed drug eruptions (FDE) typically appear within one to two weeks of the first exposure to a drug. However, in repeated exposures, this period can be up to 1-2 days. ${ }^{1}$ In FDE, oral cavity, skin and genital mucosa could be affected. Cutaneous manifestations include one or more sharply demarcated edematous plaques with a dusky center or ulceration. ${ }^{1}$ FDE may present as ulcerative aphthous stomatitis of the oral mucosa. ${ }^{43}$
Immune checkpoint inhibitor-associated oral mucositis, erosions, and ulcerations ${ }^{44}$, Mammalian (mechanistic) target of rapamycin (mTOR) inhibitorassociated stomatitis (mIAS) ${ }^{45}$, and nicorandilinduced oral ulcerations ${ }^{46}$ have also been reported in the literature.

\section{Vesiculobullous disorders}

Pemphigus vulgaris (PV), paraneoplastic pemphigus (PNP), bullous pemphigoid (BP), linear IgA bullous dermatosis (LABD), mucous membrane pemphigoid (MMP), epidermolysis bullosa acquisita (EBA) are some of the vesiculobullous disorders which can affect the oral mucosa. Since there are many causes of mouth ulcers, it is crucial to recognize the essential clinical features at the presentation.

$\mathrm{PV}$ is characterized by flaccid, intraepithelial bullae and shows oral lesions as early manifestations of the disease in nearly $50 \%$ of the cases. ${ }^{47}$ It involves both men and women with a mean age between 40 and 60 years. ${ }^{48}$ Mucosal lesions may occur first, and then disease may progress to involve the skin. ${ }^{47}$ Clinically oral lesions appear as long-lasting painful ulcers and erosions that do not heal spontaneously. Buccal mucosa, lips, and soft palate are most commonly involved. ${ }^{48}$ PNP is a rare mucocutaneous blistering disorder accompanied by both benign and malignant neoplasms. ${ }^{49}$ PNP should be kept in mind in the presence of polymorphous cutaneous eruption and severely painful, hemorrhagic oral erosions. Oral lesions frequently involve the vermilion and the tongue. ${ }^{5,49}$

BP characteristically occurs in the elderly, especially patients older than 70 years, and is associated with neurological disorders such as dementia, Parkinson's disease, and cerebrovascular diseases. ${ }^{50}$ The disease typically presents with a generalized itchy blistering eruption, although non-bullous presentations may also be seen. ${ }^{50}$ Oral involvement is seen in $10-30 \%$ of BP patients. ${ }^{51}$ The chance of seeing an intact blister on oral examination is higher in BP than in PV because of the deep subepithelial involvement. ${ }^{5}$ 
MMP is a rare subepidermal blistering disorder that predominantly involves mucosal tissues. It is more common in middle-aged women. ${ }^{52}$ Lesions may affect oral mucosa, conjunctiva, anogenital tissues, and upper aerodigestive tract and may lead to scarring in mucous membranes, skin, or both. ${ }^{53}$

In most patients, the oral mucosa is the site of onset and the most frequent area of involvement (85\%) in the disease process. ${ }^{54}$ Gingiva (80\%), buccal mucosa $(58 \%)$, and palate (26\%) are the most affected localizations in the oral mucosa.

EBA is a rare autoimmune blistering disease that has autoantibodies to collagen VII. ${ }^{55}$ Vesicle and bullae formation appear predominantly at sites of trauma. Mucosal involvement occurs in $23 \%$ of EBA patients, and the most affected localizations are the oral, ocular, and genital areas. ${ }^{55}$

LABD is characterized by tense vesicles and bullae that usually appear 1-15 days after drug exposure. ${ }^{1}$ IgA autoantibodies produced against basement membrane antigens are responsible for this entity. ${ }^{56}$ LABD could be triggered by drugs (vancomycin, penicillins, cephalosporins, insulin) and infection and may be associated with malignancy. ${ }^{56}$

\section{Trauma}

Oral traumatic ulcers are thought to be less common than aphthous stomatitis. Ulcers resulting from acute trauma are generally self-resolving without complication within 14 days; otherwise, if an ulcerative lesion lasts for two weeks or longer, it is considered as chronic ulceration and may require a biopsy to rule out neoplasia or other conditions. ${ }^{5,57}$

It may be caused by chemicals such as restorative materials, local anesthetics, sodium hypochlorite, formocresol, topical aspirin, topical oral care products, or thermal, electrical, or mechanical trauma (a sharp surface on a tooth, restoration, or denture). ${ }^{57}$

\section{Neoplasia}

Non-healing mass or persistent ulcers with indurated margins may present oral squamous cell carcinoma
(SCC). The most common localizations are lateral and ventrolateral aspects of the tongue, the mouth floor, and the buccal mucosa. ${ }^{58}$ SCC frequently occurs in areas of abnormal mucosa, such as leukoplakia, erythroplakia, or lichen planus. The presence of non-healing wounds longer than three weeks in the absence of evidence of trauma or systemic disease should raise SCC suspicion in persons over 40 years of age, male, heavily smoker, and alcohol drinker. ${ }^{58}$ Human papillomavirus (HPV) infection may also lead to oropharyngeal SCCs, particularly at the tongue base and palatine tonsils. ${ }^{59}$

Malignant lesions of B or T-cell origin such as cutaneous T-cell lymphomas (CTCL), extranodal NK/ T-cell lymphoma and EBV positive mucocutaneous ulcer may be observed in the oral cavity. ${ }^{4}$

\section{Behçet's disease}

Behçet's disease should be considered in recurrent painful oral ulcers, especially if there are accompanying genital ulcers or other mucocutaneous findings like erythema nodosum and papulo-vesiculopustular eruptions and systemic complaints. Diseaserelated oral ulcers tend to be more frequent and often multiple. ${ }^{60}$ Minor aphthous ulcers are the most common type. ${ }^{60}$ Mucosal aphthosis is the presenting sign in $80 \%$ of cases. ${ }^{1}$ Even if there is no active genital ulcer, patients with a history of genital wounds should be evaluated in terms of genital mucosa scar. If necessary, a pathergy test should be done to make the diagnosis. Ocular diseases such as anterior-posterior uveitis or retinal vasculitis, central nervous system deficits, gastrointestinal involvement, arthritis, and vascular disease may be observed. ${ }^{60}$

\section{Lichen planus}

Lichen planus is a T-cell mediated chronic inflammatory disease. ${ }^{61}$ Oral mucosal involvement may be seen alone, or other mucosa, skin, and nail involvement may accompany. In oral involvement; white, reticular, papular, plaque-like, erosive, atrophic, bullous lesions may be observed. They may be asymptomatic or painful. Buccal mucosa, lateral tongue, and gingiva are 
the most frequently affected areas. ${ }^{62}$ Hepatitis $C$ virus infection, amalgam, food additives, or dental materials may be involved in etiology. ${ }^{61,62}$ If any, like removing the amalgams, improvement can be achieved by eliminating the etiological factor, especially in related localizations.

\section{Conclusion}

Oral aphthous lesions have extensive etiologic factors and differential diagnosis. Therefore, detailed anamnesis is also very important as well as a physical examination. In the presence of any other concomitant systemic complaints or suspected malignancy findings, biopsy and additional tests may be necessary to confirm the diagnosis.

Peer-review: Externally peer-reviewed

Authorship contributions:

Conception and design, or analysis and interpretation of data: DAA, AF

Drafting the manuscript or revising the content: DAA, AF

Final approval of the version to be published: DAA

\section{References}

1. Edgar NR, Saleh D, Miller RA. Recurrent aphthous stomatitis: a review. J Clin Aesthet Dermatol 2017;10:26-36.

2. Schemel-Suarez M, Lopez-Lopez J, ChimenosKustner E. Oral ulcers: differential diagnosis and treatment. Med Clin (Barc) 2015;145:499-503.

3. Tarakji B, Gazal G, Al-Maweri SA, et al. Guideline for the diagnosis and treatment of recurrent aphthous stomatitis for dental practitioners. J Int Oral Health 2015;7:74-80.

4. Fitzpatrick SG, Cohen DM, Clark AN. Ulcerated lesions of the oral mucosa: Clinical and histologic review. Head Neck Pathol 2019;13:91-102.

5. Uzun S. Erosive, ulcerative, vesicular and bullous lesions of oral mucosa. Turkderm-Turk Arch Dermatol Venereol 2012;46:77-85.

6. Scully C. Clinical practice. Aphthous ulceration. N Engl J Med 2006;355:165-72.

7. Bratel J, Hakeberg M. Anamnestic findings from patients with recurrent aphthous stomatitis. Swed Dent J 2014;38:143-9.
8. Ma R, Chen H, Zhou T, et al. Effect of bedtime on recurrent aphthous stomatitis in college students. Oral Surg Oral Med Oral Pathol Oral Rad 2015;119:196-201.

9. Wallace A, Rogers HJ, Hughes SC, et al. Management of recurrent aphthous stomatitis in children. Oral Medicine 2015;42:564-72.

10. Sakarya U, Gundogan O, Imre A, Arslan B, Pinar E. Rekurren aftoz stomatitli 112 hastanın demografik ve labaratuvar verileri: Retrospektif inceleme. KBB-Forum 2014;13:19-25.

11. Akintoye SO, Greenberg MS. Recurrent aphthous stomatitis. Dent Clin North Am 2014;58:281-97.

12. Tappuni AR, Kovacevic T, Shirlaw PJ, et al. Clinical assessment of disease severity in recurrent aphthous stomatitis. J Oral Pathol Med 2013;42:635-41.

13. Yasui K, Kurata T, Yashiro M, et al. The effect of ascorbate on minor recurrent aphthous stomatitis. Acta Paediatrica 2010;99:442-5.

14. Lodi G, Varoni E, Robledo-Sierra J, et al. Oral ulcerative lesions. In: Contemporary Oral Medicine (Farah C, Balasubramaniam R, McCullough M, eds.), Springer,2017.

15. Shah K, Guarderas J, Krishnaswamy G. Aphthous stomatitis. Ann Allergy Asthma Immunol 2016;117:e341-3.

16. Topkarci Z. Current treatment options in challenging oral diseases: recurrent oral aphthosis Turkderm-Turk Arch Dermatol Venereol 2012;46:123-9.

17. Slebioda Z, Szponar E, Kowalska A. Recurrent aphthous stomatitis: genetic aspects of etiology. Postepy Dermatol Alergol 2013;30:96-102.

18. Slebioda Z, Krawiecka E, Szponar E, et al. Haematinic deficiencies and patient clinical profiles in Polish patients with recurrent aphthous stomatitis (RAS). J Oral Pathol Med 2018;47:531-7.

19. Orbak R, Cicek Y, Tezel A, Dogru Y. Effects of zinc treatment in patients with recurrent aphthous stomatitis. Dent Mater J 2003;22:21-9.

20. Nolan A, McIntosh WB, Allam BF, Lamey PJ. Recurrent aphthous ulceration: vitamin B1, B2 and B6 status and response to replacement therapy. J Oral Pathol Med 1991;20:389-91.

21. Scully C, Grosky M, Nur FL. Aphthous ulcerations. Dermatol Ther 2002;15:185-205.

22. Tuzun B, Wolf R, Tuzun Y, Serdaroglu S. Recurrent 
aphthous stomatitis and smoking. Int J Dermatol 2000;39:358-60.

23. Rajendran K. Relation between smoking and recurrent aphthous stomatitis. Oral Maxillofac Pathol J 2016;7:761-2.

24. Miziara ID, Auaujo-Filho BC, Weber R. AIDS and recurrent aphthous stomatitis. Rev Bras Otorhinolaringol 2005;71:517-20.

25. LeaoJC, Gueiros LA, Porter SR. Oral manifestations of syphilis. Clinics 2006;61:161-6.

26. Alam F, Argiriadou AS, Hodgson TA, et al. Primary syphilis remains a cause of oral ulceration. Br Dent J 2000;189:352-4.

27. de Andrade RS, de Freitas EM, Rocha BA, et al. Oral findings in secondary syphilis. Med Oral Patol Oral Cir Bucal 2018;23:138-43.

28. Krawiecka E, Szponar E. Tuberculosis of the oral cavity: an uncommon but still a live issue. Adv Dermatol Allergol 2015;32:302-6.

29. Whitley RJ, Kimberlin DW, Roizman B. Herpes simplex virus. Clin Infect Dis 1998;26:541-55.

30. Clarkson E, Mashkoor F, Abdulateef S. Oral viral infections: diagnosis and management. Dent Clin N Am 2017;61:351-63.

31. Kolokotronis A, Louloudiadis K, Fotiou G, et al. Oral manifestations of infections due to varicella zoster virus in otherwise healthy children. J Clin Pediatr Dent. 2001;25:107-12.

32. Ueda T, Ogata H, Kojima Y, et al. Cytomegalovirus oral ulcers. Infection 2014;42:235.

33. Reichart PA. Oral ulcerations in HIV infection. Oral Dis 1997;3:180-2.

34. Ramirez-Amador V, Esquivel-Pedraza L, SierraMadero J, et al. The changing clinical spectrum of human immunodeficiency virus (HIV)-related oral lesions in 1000 consecutive patients: a 12year study in a referral center in mexico. Medicine (Baltimore) 2003;82:39.

35. Alegre M, Dalmau J, Domingo P, et al. Successful treatment of major oral aphthous ulcers in HIV-1 infection after highly active antiretroviral therapy. Int J Infect Dis 2007;11:278.

36. Dojcinov SD, Venkataraman G, Raffeld M, Pittaluga S, Jaffe ES. EBV positive mucocutaneous ulcer-a study of 26 cases associated with various sources of immunosuppression. Am J Surg Pathol 2010;34:405-17.

37. Bunn B, van Heerden W. EBV-positive mucocutaneous ulcer of the oral cavity associated with HIV/AIDS. Oral Surg Oral Med Oral Pathol Oral Radiol 2015;120:72532.

38. Bugshan A, Farag AM, Desai B. Oral complications of systemic bacterial and fungal infections. Atlas Oral Maxillofac Surg Clin North Am 2017;25:209-20.

39. Delgado W. Oral cryptococcosis. JSM Trop Med Res 2017;2:1015.

40. Celentano A, Tovaru S, Yap T, Adamo D, Aria M, Mignogna MD. Oral erythema multiforme: trends and clinical findings of a large retrospective European case series. Oral Surg Oral Med. Oral Pathol Oral Radiol 2015;120:707-16.

41. Sokumbi O, Wetter DA. Clinical features, diagnosis, and treatment of erythema multiforme: a review for the practicing dermatologist. Int J Dermatol 2012;51:889.

42. MEDSCAPE. Toxic Epidermal Necrolysis (TEN). 2018 Available at: https://emedicine.medscape. com/article/229698-overview (last accessed 20 March 2021).

43. Ozkaya E. Oral mucosal fixed drug eruption: characteristics and differential diagnosis. J Am Acad Dermatol 2013;692:51-8.

44. Shazib MA, Woo SB, Sroussi H, et al. Oral immune related adverse events associated with PD-1 inhibitor therapy: A case series. Oral Dis 2020;26:325.

45. Chambers MS, Rugo HS, Litton JK, Meiller TF. Stomatitis associated with mammalian target of rapamycin inhibition: a review of pathogenesis, prevention, treatment, and clinical implications for oral practice in metastatic breast cancer. J Am Dent Assoc 2018;149:291-8.

46. Lee MT, Lin HY, Lee SH, et al. Risk of skin ulcerations associated with oral nicorandil therapy: a population-based study. Br J Dermatol 2015; 173:498.

47. Black M, Mignogna MD, Scully C. Number II. Pemphigus vulgaris. Oral Dis 2005;11:119-30.

48. Joly P, Litrowski N. Pemphigus group (vulgaris, vegetans, foliaceus, herpetiformis, brasiliensis). Clin Dermatol 2011;29:432-6.

49. Wieczorek M, Czernik A. Paraneoplastic pemphigus: a short review. Clin Cosmet Investig Dermatol 2016;9:291-5.

50. Amber KT, Murrell DF, Schmidt E, Joly P, Borradori L. Autoimmune subepidermal bullous diseases of 
the skin and mucosae: Clinical features, diagnosis, and management. Clin Rev Allergy Immunol 2018 ;54:26-51.

51. Di Zenzo G, DellaTorre R, Zambruno G, Borradori L. Bullous pemphigoid: from the clinic to the bench. Clin Dermatol 2012;30:3-16.

52. Bagan J, Jimenez Y, Murillo J, Bagan L. Oral mucous membrane pemphigoid: a clinical study of 100 low-risk cases. Oral Dis 2018;24:132-4.

53. Carey B, Setterfield J. Mucous membrane pemphigoid and oral blistering diseases. Clin Exp Dermatol 2019;44:732-9.

54. Setterfield J. Clinicopathological associations in mucous membrane pemphigoid. MD thesis, University of London, 2009.

55. Kridin K, Kneiber D, Kowalski EH, et al. Epidermolysis bullosa acquisita: a comprehensive review. Autoimmun Rev 2019;18:786-95.

56. Chaudhari S, Mobini N. Linear IgA bullous dermatosis: a rare clinicopathologic entity with an unusual presentation. J Clin Aesthet Dermatol 2015;8:43-6.

57. Munoz-Corcuera M, Esparza-Gomez G, GonzalezMoles MA, et al. Oral ulcers: clinical aspects. A tool for dermatologists. Part I. Acute ulcers. Clin Exp Dermatol 2009;34:289-94.

58. Ellington TD, Henley SJ, Senkomago V, et al. Trends in incidence of cancers of the oral cavity and pharynx - United States 2007-2016. MMWR Morb Mortal Wkly Rep 2020;69:433.

59. Kalavrezos N, Scully C. Mouth cancer for clinicians part 6: potentially malignant disorders. Dent Update 2015;42:866-8.

60. Yazici Y, Yurdakul S, Yazici H. Behcet's Syndrome. Curr Rheumatol Rep 2010;12:429-35.

61. Lavanya N, Jayanthi P, Rao UK, Ranganathan K. Oral lichen planus: an update on pathogenesis and treatment. J Oral Maxillofac Pathol. 2011;15:127-32.

62. Muller S. Oral lichenoid lesions: distinguishing the benign from the deadly. Mod Pathol 2017;30:54-67. 